\title{
sciendo RESULTS OF A STUDY ON THE QUALITY OF CONICAL PICKS FOR PUBLIC PROCUREMENT PURPOSES
}

DOI 10.2478/ntpe-2018-0087

\author{
Łukasz Bołoz, PhD. Eng. \\ AGH University of Science and Technology, Poland
}

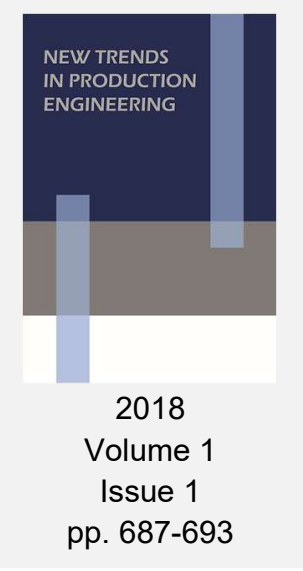

\begin{abstract}
The article presents the results of a study on the quality of conical picks for the purposes of tender procedures in accordance with the public procurement law in Poland. The pick studies presented here are one of the few that in practice allow the selection of an offer based on objectively determined numerical indicators defining the quality of the product and not only on the basis of price. Thanks to this, the contracting party can decide the relevance of price and quality in their evaluation of a pick. The geometrical and material parameters required in a tender, if not met, are the basis for rejecting a given offer of picks. The numerical parameter influencing the final evaluation of the offer is the picks' rate of wear. Conical picks are tools for mining minerals, rocks, asphalt or concrete. They are used in many industries, especially in mining, construction and road engineering. In difficult working conditions, the durability of knives is limited to as little as several hours. Several dozen picks work on a cutting unit at the same time, and taking into account the price of a knife which oscillates around several dozen euros, significant operating costs are incurred. Therefore, the selection of tools with an optimum price-quality ratio is crucial. The article presents the results of studies on geometric parameters, material parameters and the rate of wear of 48 sets of picks conducted for a tender consisting of 14 tasks. The tender was conducted for 6 underground mines of a coal company. Five producers submitted their offers for selected tasks in the tender.
\end{abstract}

Keywords: conical picks, offer selection, public tenders, durability

\section{INTRODUCTION}

Conical picks known in Poland as tangential-rotary picks are tools widely used in mining, construction and road engineering. Depending on the working conditions, their wear rate varies from several to several dozen per day for one mining machine, and their price oscillates around several dozen euros. In terms of numbers, the most knives are used in underground mines. The costs incurred by one mine due to the purchase of conical picks are estimated at several million euros per year. Users strive to use the best picks available, however the selection of the best offer is complicated, as the quality of the knife is the product of many factors. Above all, abrasive wear resistance as well as geometrical and material parameters are important. The picks offered for mines differ significantly in price, however, it is often not adequate to their durability. That is why a parametric evaluation of the quality of conical picks was developed and implemented, allowing for the selection of the optimal offer. The procedure uses the methods of measurement and laboratory tests. The methodology also applies to control tests that allow verification of the quality of picks delivered and, as a result, maintaining the quality of deliveries.

\section{CONICAL PICKS}

Exploitation of longwall excavations and headings in underground mining is done mainly using mechanical mining. Mechanical mining consists in directly working a rock face with a mining tool. The most popular mining methods are shearing and ploughing, and are carried out with cutting tools. At present, the conical picks are the standard tool mounted on cutting heads worldwide. Cutting heads are the most important elements of mining machines and the 
durability of picks has an impact on operating costs, available machine working time and energy consumption of the entire process. Meeting users' expectations, then, depends to a large extent on the correct selection and quality of cutting tools. The conical pick is an element which is in contact with the rock face. It is the pick that is directly responsible for the mining process. The shape of the pick and its proper fixing to the head allows it to rotate freely, which results in an even wear of the cutting edge. Due to the working conditions and the specificity of the mining machine, picks differ in geometry (shape, size, method of fixing), material and the method of protecting the body against abrasive wear.

A standard conical pick, shown in Fig. 1, consists of a cone-shaped working part, a cylindrical mandrel which is the pick's gripping part and a cutting edge in the form of an insert made of cemented carbide.

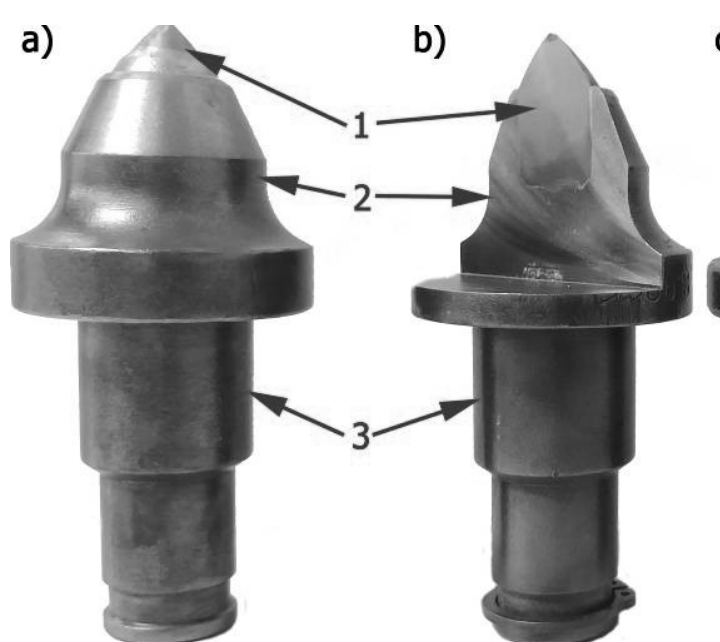

Fig. 1. Structure and example solutions of conical picks

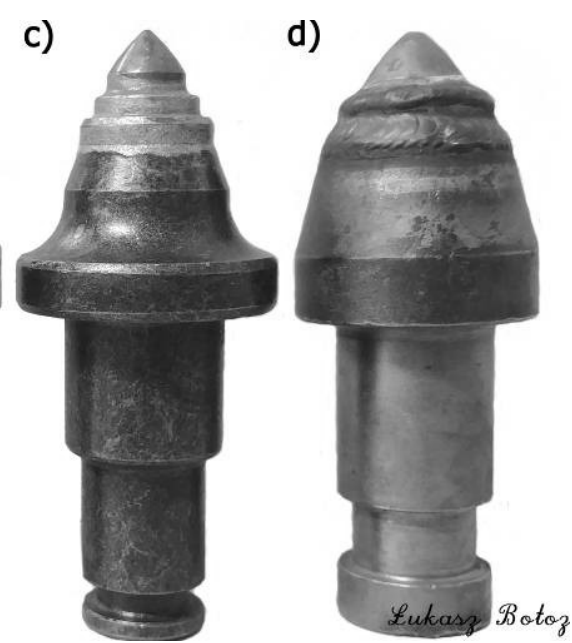

a. structure of a typical pick, b. cross-section of a pick's working part, c. pick with a cemented carbide ring, $d$. pick with an anti-abrasive coating

1 - cutting edge made of cemented carbide, 2 - working part, 3 - gripping part.

The conical picks are the subject of research and development works carried out in many centres around the world. These studies are mainly aimed at finding a solution with the highest abrasion resistance. Knives were tested, whose the body was protected against abrasive wear with wear-resistant coatings, pad welding or cemented carbide rings (Krauze et al., 2017, Chang and Chulho, 2017). Studies was carried out to learn about the mechanism of abrasive wear of knives (Dewangan and Chattopadhyaya, 2015), wear prediction (Gajewski et al., 2013) or the possibility of supporting the mining process (Kotwica, 2011). Tests were carried out for the cemented carbide material (Nahak et al., 2015) as well as the entire pick (Dewangan et al., 2015, Songyong et al., 2017) and picks forming the cutting tool (Krauze et al., 2015, Krauze and Kotwica, 2007). Implementation works were also carried out to apply modern tools and cutterheads to difficult conditions (Bołoz and Krauze, 2018, Krauze and Bołoz, 2018). As a result, information about qualitative and quantitative wear was obtained. These tests were a part of research and local in nature and are only useful to a small extent to the users of picks.

The pick with specific parameters chosen for the given conditions can be supplied to the user by different manufacturers. However, manufacturers do not specify the quality and durability of picks in a way that allows their objective comparison and selection of the best option, before the purchase.

Mining companies that are required to use public tender procedures often use the price of the pick as the only criterion when selecting an offer. However, the price does not reflect the quality. So far, users have not had the right procedure to assess the quality of picks in an unambiguous manner and apply the results of this assessment as a criterion when selecting the optimal offer. Therefore, considering the public procurement law, it was necessary to 
develop a method of testing picks which would allow for selecting the best offer at the lowest possible price.

It is worth noting that the wear of conical picks, both quantitative and qualitative, differs from the idea of the wear of machine parts prevalent in other industries. Fig. 2 presents examples of used picks encountered in practice. Figure $2 a$ shows a pick that is asymmetrically worn, which caused destruction of the gripping part. Figure $2 \mathrm{~b}$ show a pick worn symmetrically due to excessively long operation time. In Figure $2 \mathrm{c}$ the pick is worn asymmetrically, and has also been deformed plastically. Fig. $2 \mathrm{~d}$ and e present pick with pad welds, working properly under abrasive conditions, suitable for further use. To illustrate the scale of wear, the shape of brand new picks was applied to the pictures of the picks.

\section{EVALUATION OF THE QUALITY OF CONICAL PICKS}

Proper and long operation of properly selected conical picks depends on the geometrical parameters of the pick body and the cemented carbide, material parameters of the pick body and cutting edge as well as durability of the entire pick. The research was carried out in accordance with the original procedure presented in the literature (Krauze et al., 2015).
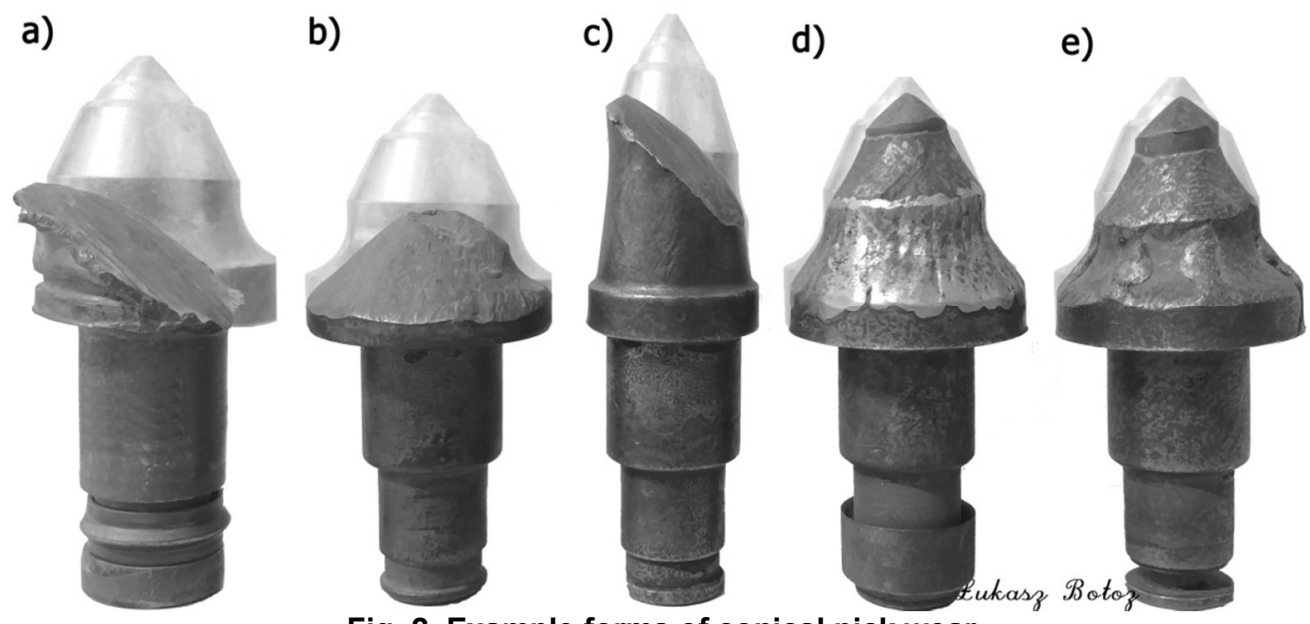

Fig. 2. Example forms of conical pick wear a and c - asymmetrical, b, d, e - symmetrical.

The durability of picks is the most important element that characterizes their quality, but it is also recommended to control the geometrical and material parameters of the body and the insert (Krauze et al., 2015). The presented procedure was implemented in three Polish coal companies.

The measurement of geometrical and material properties was carried out using regular, standardized methods. The wear rate tests were carried out at a unique test stand (Figure 3).

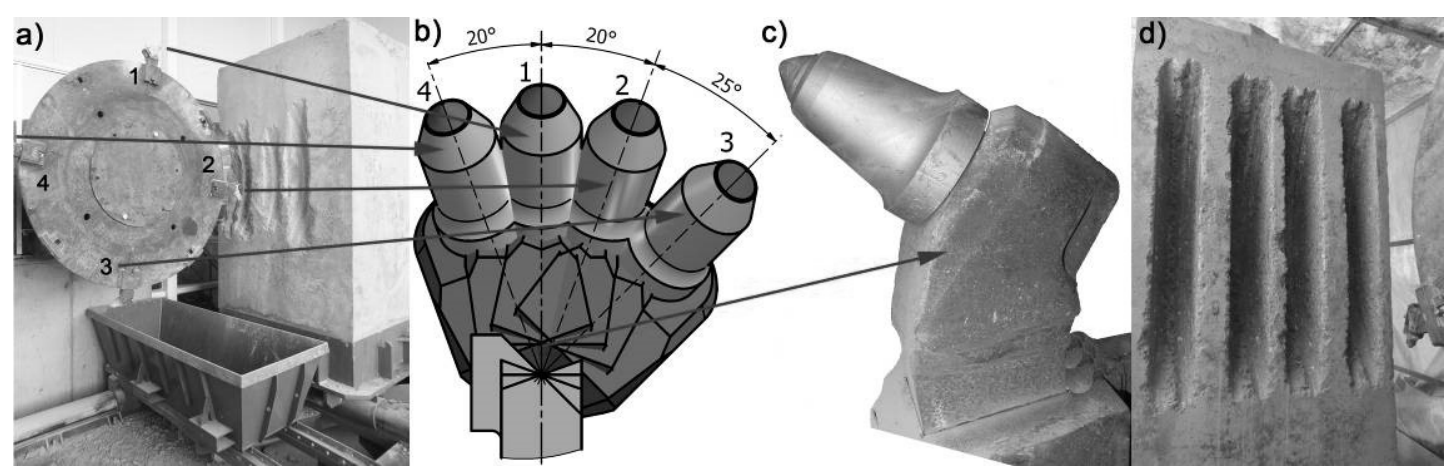

Fig. 3. Wear rate test stand, a. test sample, b. pick positioning, c. example pick in a handle, d. sample after testing. 
These tests involved the milling of an artificial concrete sample with knives in controlled conditions and measuring the loss of their mass during this process. The loss of mass of the picks and the volume of the sample milled made it possible to calculate the numerical wear index. The lower the index value, the higher the durability of the picks.

\section{SUBJECT OF RESEARCH}

The article presents the results of tests from one of the tenders, which concerned the supply of 371,640 picks over a period of two years. The tender consisted of 14 tasks, i.e. 14 different types of picks, which were intended for 6 mines. Five producers took part in the tender for the individual tasks. Table 1 lists the consecutive tasks with pick type, number of items and the share of the individual companies. Pick type is recorded using its characteristic values, such as the diameter of the carbide insert, the total length, the length of the working part and the diameter of the grip part. In addition, the pick type specifies the type of pick protection applied and optional information on the presence of an anti-abrasive coating. The number of pieces refers to the required number of picks that the supplier must provide within two years. The participation of tenderers in individual tasks was assigned using company symbols $C, G, K, S$ and $\mathrm{Y}$.

In practice, each of the bidders in the tender provided a representative sample of 22 picks for each task. In accordance with the procedure 3 picks were used for geometry tests, another 3 for material tests and 4 for wear rate tests. The remaining 12 picks were a quality benchmark. In a situation where the mine had suspicions about the quality of picks delivered, it provided 10 pieces which were checked in terms of geometric parameters (3 pieces), material parameters ( 3 pieces) and wear rate (4 pieces) by comparison with standard picks (4 pieces). Based on the results of the tests, conclusions confirming or rejecting the mine's claims were drawn. The complaint procedure has been used only in a few cases, which proves that the manufacturers maintain the high quality of the picks. In total, 48 sets of picks were tested, i.e. 1056 pieces, of which 576 were designated as a reference in case of possible future complaints.

Table 1.

Juxtaposition of basic information about the subject of research.

\begin{tabular}{|l|l|c|c|c|c|c|c|}
\hline \multirow{2}{*}{ Task } & \multicolumn{1}{|c|}{ Pick type } & \multirow{2}{*}{$\begin{array}{c}\text { Number } \\
\text { of pieces }\end{array}$} & \multicolumn{5}{c|}{ Part. in tasks } \\
\cline { 5 - 7 } & & & C & G & K & S & Y \\
\hline 1. & $\varnothing 25 / 147 / 70 / 58 / 38$ & 62000 & $\vee$ & $\vee$ & $\vee$ & $\vee$ & $\vee$ \\
\hline 2. & $\varnothing 25 / 140 / 65 / 65 / 38-30$ & 95400 & $\vee$ & $\vee$ & $\vee$ & $\vee$ & $\vee$ \\
\hline 3. & $\varnothing 25 / 140 / 65 / 55 / 30$ & 10000 & $\vee$ & $\vee$ & $\vee$ & - & $\vee$ \\
\hline 4. & $\varnothing 22 / 145 / 65 / 48 / 30$ & 15000 & $\vee$ & $\vee$ & $\vee$ & - & - \\
\hline 5. & $\varnothing 22 / 170 / 90 / 48 / 30$ & 15000 & $\vee$ & $\vee$ & $\vee$ & - & - \\
\hline 6. & $\varnothing 22 / 145 / 65 / 52 / 30 \mathrm{PC}$ & 21000 & $\vee$ & $\vee$ & $\vee$ & - & - \\
\hline 7. & $\varnothing 22 / 185 / 90 / 60 / 38$ & 3840 & $\vee$ & $\vee$ & $\vee$ & - & - \\
\hline 8. & $\varnothing 22 / 165 / 90 / 65 / 38-30$ & 66900 & $\vee$ & $\vee$ & $\vee$ & - & - \\
\hline 9. & $\varnothing 22 / 165 / 90 / 65 / 38-30 \mathrm{HZ}$ & 18000 & $\vee$ & $\vee$ & $\vee$ & - & - \\
\hline 10. & $\varnothing 18 / 165 / 60 / 38-30 \mathrm{HZ}$ & 6000 & $\vee$ & $\vee$ & $\vee$ & - & - \\
\hline 11. & $\varnothing 25 / 165 / 90 / 65 / 38-30 \mathrm{HZ}$ & 3500 & $\vee$ & $\vee$ & $\vee$ & - & - \\
\hline 12. & $\varnothing 20 / 140 / 64 / 62 / 38-30$ with coating & 25000 & - & $\vee$ & $\vee$ & $\vee$ & - \\
\hline 13. & $\varnothing 20 / 144 / 64 / 52 / 30$ with coating & 15000 & - & $\vee$ & $\vee$ & $\vee$ & - \\
\hline 14. & $\varnothing 25 / 144 / 64 / 52 / 30$ & 15000 & $\vee$ & $\vee$ & $\vee$ & $\vee$ & - \\
\hline
\end{tabular}

\section{RESULTS OF CONICAL PICK QUALITY EVALUATION}

In most cases, conical picks are turned and their cutting tips are sintered and soldered to the bodies. Maintaining dimensional accuracy is not problematic and manufacturers usually meet the requirements. In the case analysed, the exception was the $Y$ company, which had recently undertaken the production of mining picks. In the first task, all picks from said company had an 
incorrect length and an incorrect blade angle, while in task 2 and 3 all picks had an incorrect blade angle.

Material tests have shown isolated cases of non-compliance. Most often, the permissible hardness of the pick's grip part was exceeded, as was the case for company $C$ (task 2, 8, 9), $\mathrm{G}$ (task 11, 12), $\mathrm{K}$ (task 6, 7, 8, 9, 10, 12), $\mathrm{S}($ task 1) and $\mathrm{Y}$ (task 1, 2, 3). There were occasional cases of the ranges of carbon, chromium or manganese content being exceeded, as in the case of company $\mathrm{G}$ (task $1,2,3,4,5), \mathrm{K}$ (task 1) and $\mathrm{S}$ (task $1,2,13$ ). The $\mathrm{Y}$ company used $42 \mathrm{CrMo} 4$ steel for knife bodies, the remaining companies used $35 \mathrm{HGS}$ steel. The $\mathrm{Y}$ company used B40 carbides, while the other companies opted for the B2, B20 and B23 grades.

The durability tests were carried out on a concrete sample with strength $R_{c}=11.49 \mathrm{MPa}$. Four picks were tested simultaneously for each task and producer. The picks were mounted on a test disk with a diameter of approximately $1850 \mathrm{~mm}$ and a width of approximately $155 \mathrm{~mm}$. The tests lasted 5 minutes during which the picks milled $140 \mathrm{~mm}$ of concrete. The average wear of each pick oscillated around $20 \div 30$ grams, ranging from a few grams up to even 70 grams in extreme cases. The calculated values of wear rate indicators are presented in table form (Table 2) and graphically (Fig. 4).

Table 2.

Juxtaposition of wear rate test results.

\begin{tabular}{|c|c|c|c|c|c|}
\hline Task & $\mathbf{C}$ & $\mathbf{G}$ & $\mathbf{K}$ & $\mathbf{S}$ & $\mathbf{Y}$ \\
\hline $\mathbf{1 .}$ & 1.055 & $\mathbf{0 . 8 0 1}$ & 0.916 & 0.910 & 1.076 \\
\hline $\mathbf{2 .}$ & 0.922 & 1.078 & 0.978 & $\mathbf{0 . 8 6 9}$ & 1.475 \\
\hline $\mathbf{3 .}$ & $\mathbf{1 . 0 3 2}$ & 1.170 & 1.376 & - & 1.468 \\
\hline $\mathbf{4 .}$ & 2.158 & 1.890 & $\mathbf{1 . 7 9 3}$ & - & - \\
\hline $\mathbf{5 .}$ & $\mathbf{0 . 8 4 5}$ & 1.063 & 0.846 & - & - \\
\hline $\mathbf{6 .}$ & 2.082 & 1.876 & $\mathbf{1 . 8 7 5}$ & - & - \\
\hline $\mathbf{7 .}$ & $\mathbf{1 . 0 5 8}$ & 1.136 & 1.099 & - & - \\
\hline $\mathbf{8 .}$ & 1.680 & $\mathbf{1 . 5 3 7}$ & 1.582 & - & - \\
\hline $\mathbf{9 .}$ & 1.343 & $\mathbf{1 . 0 1 0}$ & 1.024 & - & - \\
\hline $\mathbf{1 0 .}$ & 2.174 & $\mathbf{1 . 7 8 9}$ & 2.349 & - & - \\
\hline $\mathbf{1 1 .}$ & 2.230 & 2.047 & $\mathbf{1 . 9 2 0}$ & - & - \\
\hline $\mathbf{1 2 .}$ & - & 0.500 & 0.876 & $\mathbf{0 . 2 5 5}$ & - \\
\hline $\mathbf{1 3 .}$ & - & 0.790 & 0.822 & $\mathbf{0 . 6 7 0}$ & - \\
\hline $\mathbf{1 4 .}$ & $\mathbf{1 . 0 1 7}$ & 1.217 & 1.033 & 1.326 & - \\
\hline Won: & $\mathbf{4}$ & $\mathbf{4}$ & $\mathbf{3}$ & $\mathbf{3}$ & $\mathbf{0}$ \\
\hline
\end{tabular}

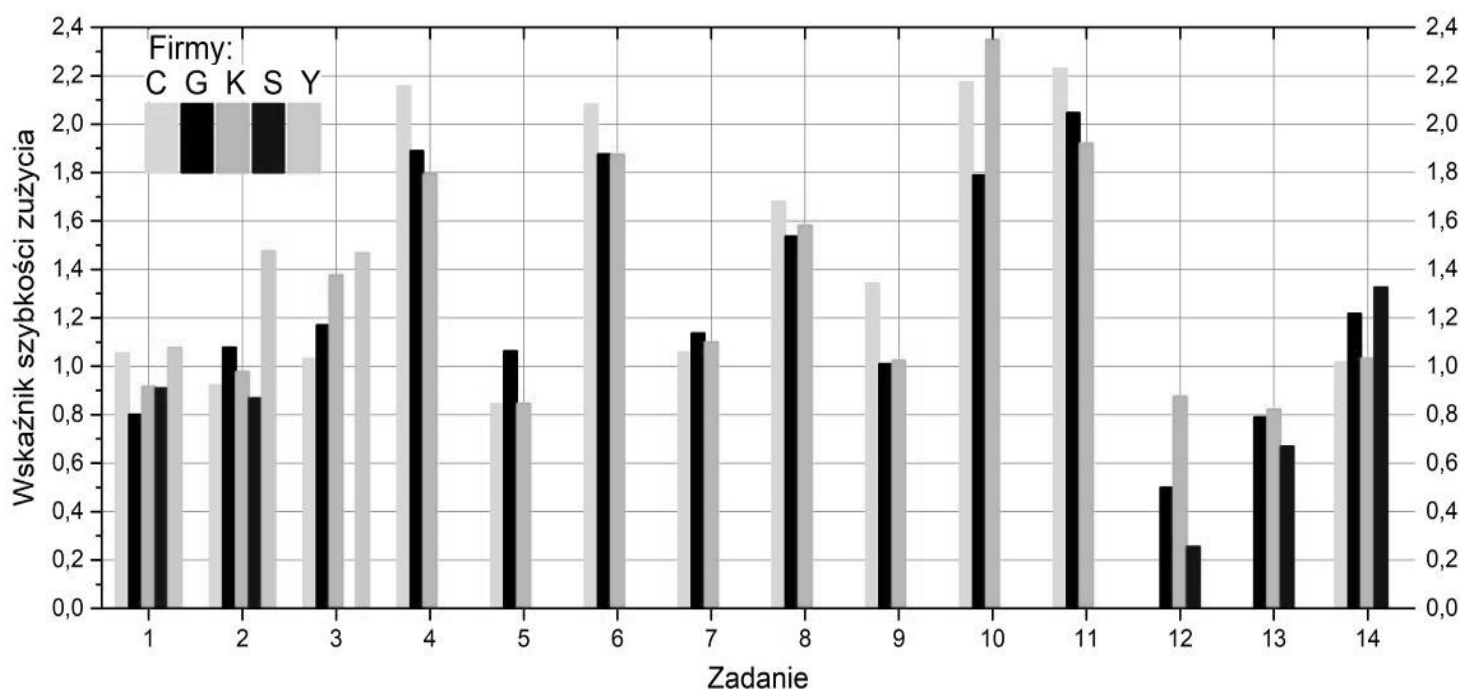

Fig. 4. Graphic representation of pick wear rate test results. 
The durability tests were carried out on a concrete sample with strength $R_{c}=11.49 \mathrm{MPa}$. Four picks were tested simultaneously for each task and producer. The picks were mounted on a test disk with a diameter of approximately $1850 \mathrm{~mm}$ and a width of approximately $155 \mathrm{~mm}$. The tests lasted 5 minutes during which the picks milled $140 \mathrm{~mm}$ of concrete. The average wear of each pick oscillated around $20 \div 30$ grams, ranging from a few grams up to even 70 grams in extreme cases. The calculated values of wear rate indicators are presented in table form (Table 2) and graphically (Fig. 4). Table 2 highlights picks that achieved the highest durability in a given task. Worthy of note is the comparison of results between individual tasks. A characteristic trend is the significantly reduced wear of picks with anti-abrasive coatings (tasks 12 and 13). A view of the sample picks from each task from 1 to 14 (left to right) is shown in Figure 5.

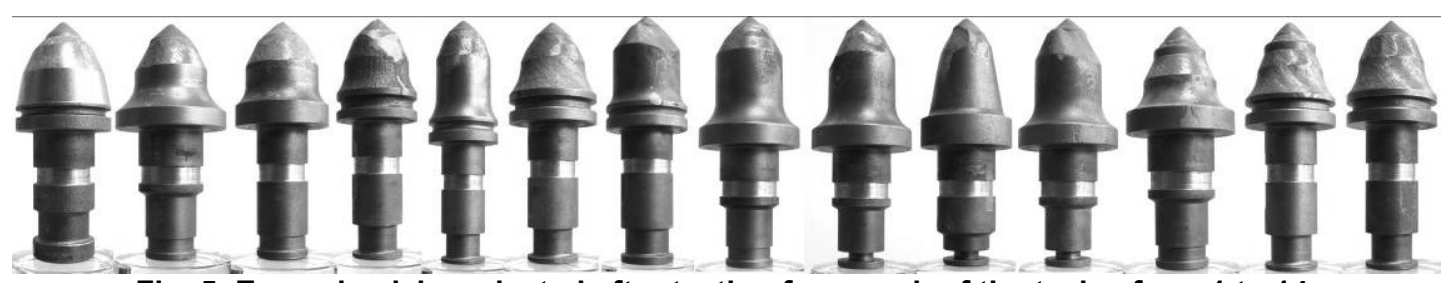

Fig. 5. Example picks selected after testing from each of the tasks, from 1 to 14.

\section{CONCLUSION}

Milling with conical picks, especially in underground mining, is used on a large scale. The correct operation of conical picks guarantees high durability of cutting units with low energy consumption, dustiness and sparking. Technically, the manufacturer is not able to give information on the durability of his product in such a way that it is possible for the user to compare the offers of different manufacturers with one another. Therefore, an appropriate research methodology was developed for the needs of Polish coal companies. Based on the analysis of the results of tests consisting of three stages, taking into account the price, it is possible to select the optimal offer and control the quality of the product delivered.

The results of the geometrical, material and wear rate tests indicate high quality of the picks. Only one manufacturer did not meet the geometrical requirements. The pick manufacturer has no control over the material composition of the steel, hence the responsibility for sporadic exceedances of the standards lie with the material supplier. In the case of some picks, the problem was to maintain the hardness of the grip part in the limit of $30 \mathrm{HRC} \pm 5 \mathrm{HRC}$ while ensuring hardness of the working part above $45 \mathrm{HRC}$. The rate of wear of the picks, which represents their durability, varied largely for individual producers and tasks. With reference to the best pick in each task, the durability of the other picks offered in that task ranged from from $9 \%$ to over $243 \%$. However, the best pick across all tasks wore down slower than the worst one by $821 \%$. It should be noted that differences in the price of picks within one task exceeded one hundred percent. Hence, the selection of an optimal offer, without objective information about quality, is difficult and has financial consequences. The results presented in the article were obtained with a study of picks offered by five manufacturers operating on the Polish market. Thanks to the implementation of the tests described in the present article, an over twofold reduction in the wear of picks was registered.

\section{ACKNOWLEDGEMENTS}

The works were carried out within the framework of the Dean's Grant under the Agreement No. 15.11.130.838.

\section{REFERNCES}

Bołoz $Ł$, Krauze K. (2018). Ability to mill rocks in open-pit mining. In: 18th International Multidisciplinary Scientific Geoconference, Exploration and Mining, SGEM2018, Albena, Bulgaria, Voulme 2.

Chang S., Lee, Chulho, Kang. (2017). Tae-HoEffect of hardfacing on wear reduction of pick cutters under mixed rock conditions. Geomechanics and engineering, 13(1), pp. 141-159. 
Dewangan, Saurabh, Chattopadhyaya, Somnath, (2015). Critical Analysis of Wear Mechanisms in Cemented Carbide. Jorunal of materials engineering and performance, 24(7), pp. 2628-2636.

Dewangan, Saurabh; Chattopadhyaya, Somnath; Hloch, Sergej. (2015). Wear Assessment of Conical Pick used in Coal Cutting Operation. Rock mechanics and rock engineering, 48(5), pp. 2129-2139.

Gajewski J., Jedlinski L., Jonak J. (2013). Classification of wear level of mining tools with the use of fuzzy neural Network. Tunnelling and underground space technology, 35, pp. 3036.

Kotwica K. (2011). The influence of water assistance on the character and degree of wear of cutting tools applied in roadheaders. Archives of Mining Sciences, 5(3), pp. 353-374.

Krauze K., Bołoz Ł.(2018). Disc unit dedicated to mine abrasive rocks and in particular copper ores. In: 18th International Multidisciplinary Scientific Geoconference, Exploration and Mining, SGEM2018, Albena, Bulgaria, Voulme 2.

Krauze K., Bołoz Ł., Wydro T. (2015). Parametric factors for the tangential-rotary picks quality assessment, Archives of Mining Sciences, 60(1), pp. 265-281.

Krauze K., Bołoz Ł., Wydro T., Mucha K. (2017). Durability testing of tangential-rotary picks made of different materials. Mining - Informatics, Automation and Electrical Engineering, 1, pp. 26-34.

Krauze K., Kotwica K. (2007). Selection and underground tests of the rotary tangential cutting picks used in cutting heads of the longwall and roadway miners. Archives of mining science, 52(2), pp. 195-217.

Nahak, Sakuntala; Dewangan, Saurabh; Chattopadhyaya, Somnath. (2015). Discussion on Wear Phenomena in Cemented Carbide. In: Global Challenges, Policy Framework \& Sustainable Development for Mining of Mineral and Fossil Energy Resources. Dhanbad: GCPF, 11, pp. 284-293.

Songyong L., Huifu; J., Xiaohui L. (2017). Experimental research on wear of conical pick interacting with coal-rock. Engineering failure analysis, 74, pp. 172-187. 